This item was submitted to Loughborough's Research Repository by the author.

Items in Figshare are protected by copyright, with all rights reserved, unless otherwise indicated.

\title{
Understanding the impact of trunk and arm impairment on wheelchair rugby performance during competition
}

PLEASE CITE THE PUBLISHED VERSION

https://doi.org/10.1123/ijspp.2018-0204

\section{PUBLISHER}

(c) Human Kinetics, Inc.

\section{VERSION}

AM (Accepted Manuscript)

\section{PUBLISHER STATEMENT}

This work is made available according to the conditions of the Creative Commons Attribution-NonCommercialNoDerivatives 4.0 International (CC BY-NC-ND 4.0) licence. Full details of this licence are available at: https://creativecommons.org/licenses/by-nc-nd/4.0/

\section{LICENCE}

CC BY-NC-ND 4.0

\section{REPOSITORY RECORD}

Mason, Barry, Viola C. Altmann, and Vicky Goosey-Tolfrey. 2019. "Understanding the Impact of Trunk and Arm Impairment on Wheelchair Rugby Performance During Competition". figshare.

https://hdl.handle.net/2134/35347. 
Understanding the impact of trunk and arm impairment on wheelchair rugby performance during competition

Original Investigation

Barry S. Mason, ${ }^{1}$ Viola C. Altmann, ${ }^{2}$ Victoria L. Goosey-Tolfrey. ${ }^{1}$

${ }^{1}$ Peter Harrison Centre for Disability Sport, School of Sport, Exercise \& Health Sciences, Loughborough University, UK

${ }^{2}$ Sint Maartenskliniek, Department of Rehabilitation, Nijmegen, the Netherlands.

Running head: Wheelchair rugby classification

\section{Corresponding author:}

Dr. Barry Mason, Peter Harrison Centre for Disability Sport,

School of Sport, Exercise \& Health Sciences, Loughborough University

Loughborough, LE11 3TU, UK

Phone: +44 (0)1509 226387; Email: b.mason@lboro.ac.uk

Abstract word count: 245 words

Text word count: 3329 words

Figures / Tables: 3 figures / 4 tables 


\section{Abstract}

2 Purpose: To determine the effect of trunk and arm impairment on physical and technical 3 performance during wheelchair rugby (WR) competition. Methods: Thirty-one highly trained 4 WR players grouped according to their trunk (no trunk [NT]; some trunk [T] function) and

5 arm impairment (poor [PAF]; moderate [MAF]; good [GAF] arm function) participated in 5 6 WR matches. Player's physical (wheelchair mobility) and technical (ball handling) activities 7 were analysed using an indoor tracking system and video analysis respectively. Results:

8 Trunk impairment explained some of the variance in physical (10.6-23.5\%) and technical 9 (16.2-33.0\%) performance. $\mathrm{T}$ covered more distance, had more possession, scored more goals, received and made more passes, yet spent less time at low speeds and performed fewer

11 inbounds than NT $(\leq 0.05)$. Arm impairment explained some of the variance in all physical 12 (16.7-47.0\%) and the majority of technical (13.1-53.3\%) performance measures. MAF and 13 GAF covered more distance, reached higher peak speeds, spent more time in higher speed 14 zones, scored more goals, had more possession, received and made more passes, with a higher percentage of one-handed and long passes than PAF. GAF also received more passes and made a higher percentage of one-handed passes and defensive blocks than MAF ( $P \leq$

17 0.05). Conclusions: Arm impairment impacts a greater number of physical and technical measures of performance specific to WR than trunk impairment during competition. Having active finger function (GAF) yielded no further improvements in physical performance but positively influenced a small number of technical skills.

22 Keywords: activity limitation; classification; Paralympic sport; activity profiles 
Introduction

Wheelchair rugby (WR) is a Paralympic team sport originally developed for individuals with tetraplegia resulting from a spinal cord injury (SCI), with other impairments such as multiple amputations, cerebral palsy and neuromuscular diseases also eligible to 27 participate. ${ }^{1}$ As with most Paralympic sports, a classification system exists in order to 28 minimise the impact of impairment on the outcomes of competition. ${ }^{2}$ Classification in WR is largely dependent on the physical assessment of trunk and arm function. Point scores between 0-1.5 are awarded to represent trunk function. Both arms are scored between 0.5-3.5 and then averaged to provide an 'arm score', which is added to the 'trunk score' to give an overall classification. Currently, players are classified into one of seven categories ranging from 0.5 (most impaired) to 3.5 (least impaired) at 0.5 increments. Rules stipulate that teams are allowed 4 players not exceeding 8.0 points on court at a given time. ${ }^{1}$ performance have been investigated during competition. Yet, these studies have only considered the overall classification, with players typically allocated into low- $(\leq 1.5)$ and high-point ( $\geq 2.0$ ) groups and have failed to consider the individual contribution of trunk and arm impairment towards performance. Recently, during standardised WR field testing it has been revealed that trunk impairment affected acceleration performance and the impulse of a

41 hit, whereby arm impairment influenced sprinting (> $2 \mathrm{~m})$ and manoeuvrability 42 performance. ${ }^{8,9}$ However, the effect of trunk and arm impairment on technical aspects of WR 43 performance have not been examined and the impact of these impairments upon activity 44 limitation has never been investigated during competition. This type of research would 45 further understanding about activity limitations under sport-specific conditions, as advocated by the International Paralympic Committee. ${ }^{2}$ 

impairment on physical and technical aspects of WR performance during competition. It was hypothesised that trunk impairment would affect physical measures, whereas arm impairment would have more of a bearing on technical measures of performance. The findings of this

51 study will increase our understanding of impairment of the trunk and the arms and their 52 specific effects on performance. This information could benefit coaches, athletes and practitioners from a performance perspective. Furthermore it could benefit classifiers, and both the International Wheelchair Rugby Federation (IWRF) and the International Paralympic Committee to move towards an evidence-based classification system.

56

\section{Methods}

\section{Participants}

Highly trained WR players $(n=31$; age $=31 \pm 7$ years; international playing experience $=8 \pm 6$ years; range $=1-24$ years) from 3 of the world top 10-ranked

61 international teams in 2015 participated in the study. Players all had a confirmed international 62 classification and presented for the following health conditions: SCI ( $n=21)$, neuromuscular disease $(n=3)$, cerebral palsy $(n=2)$ and skeletal dysplasia $(n=5)$. Players were grouped according to their trunk and arm impairment scores. Impairment was determined by licenced IWRF classifiers, based on the IWRF classification manual ( $3^{\text {rd }}$ edition, revised 2015). ${ }^{10}$. The score for arm impairment, ranging from 0.5 - 3.5 with 0.5 increments, was based on Manual

67 Muscle Testing (MMT) according to the methodology of “Daniels and Worthingham's muscle testing" ${ }^{11}$ for those with impaired muscle strength. Athletes with other eligible impairment types are classified based on a similar impact of this impairment on the ability to perform activities in wheelchair rugby. ${ }^{10}$. The score for trunk impairment, ranging from 0 -

71 1.5, also with 0.5 increments, was based on Trunk Impairment Classification. ${ }^{12}$. In brief, those 
72 with complete paralysis of all trunk muscles were categorised as 'no trunk' (NT; trunk score

$73=0 ; n=18$ ), while those with moderate to good trunk function were categorised as 'trunk' ( $\mathrm{T}$;

74 trunk score $=0.5-1.5 ; n=13$ ). Players with muscle weakness (MMT 0-3) around the 75 shoulders, elbows and wrists and no active finger function were categorised as 'poor arm 76 function' (PAF; arm score $\leq 1.5 ; n=12$ ). Those with no muscle weakness (MMT 4-5) around 77 the shoulders, elbows and wrists, but with minimal to no active finger function were classed as 'moderate arm function' (MAF; arm score $=2.0 ; n=13$ ). In addition to the characteristics of MAF, players with significant active finger function were classed as having 'good arm function' (GAF; arm score $\geq 2.5 ; n=6$ ). The difference between PAF and MAF/GAF is mainly the strength in the proximal muscles around the shoulders and the elbows. Both MAF and GAF have no muscle weakness around the shoulders and the elbows, but GAF have more function in the fingers. The combinations of trunk and arm scores for all participants are displayed in Table 1. All procedures outlined in the study were approved by Loughborough University’s ethical advisory committee and all players provided written informed consent.

\section{INSERT TABLE 1 HERE}

\section{Procedures}

Data were collected at an international WR competition in 2015. The three

91 participating teams each competed in 5 matches over 5-days on the same indoor court ( $28 \mathrm{x}$

$9215 \mathrm{~m})$. Physical data about players’ individual activity profiles and technical data relating to ball handling activities were monitored during all matches using player tracking technology and video analysis respectively. Data was collected during every instance that a player was on court. A total of 390 individual observations were collected, with an observation defined 
as a period whereby a player was on court during each quarter. The mean playing time per quarter across all players was 02:06 \pm 01:07 and ranged from 00:22 to 04:41 (hh:mm).

Activity profiles were collected during matches using a radio-frequency based indoor tracking system (ITS) operating at $8 \mathrm{~Hz}$ (Ubisense, Cambridge, UK), which has been validated $^{13}$ and used to quantify the physical demands of WR competition., ${ }^{3,4}$. Data collection commenced at the beginning and ceased at the end of each quarter and was only paused during periods of delayed stoppages. Raw positional data were filtered according to previous guidelines $^{13}$ and then used to calculate the following: i) relative distance (distance covered per minute of playing time); ii) peak speed (highest speed observed across all match observations); iii) relative time spent in a total of six arbitrary speed zones (Z1-Z6), for all players (Table 2). These parameters were included based on their previous association with successful performance in $\mathrm{WR} .{ }^{4}$ Only individual match observations lasting $\geq 3$ minutes were processed for all players across all matches.

\section{INSERT TABLE 2 HERE}

Technical data were collected during matches using 2 synchronised video cameras (Sony HDR-HC9, Tokyo, Japan). Each camera was equipped with a wide angle conversion lens (Raynox HD-5050PRO, Tokyo, Japan) and positioned at the halfway line. Video footage was analysed using Dartfish TeamPro Data 6.0 (Fribourg, Switzerland) by one analyst experienced with both the software and WR. Descriptions of the coded activities are displayed in Table 3. These technical activities were selected based on previous research, which has emphasised the importance of these parameters in overall performance in WR. ${ }^{6,7}$ Since the duration of match-play varied between players across the competition, frequency statistics (goals scored, passes received etc.) were scaled up or down to represent the 
121 frequency of occurrences of each activity relative to a 32-minute match, using the total times

122 from the ITS. A whole quarter of match play for each of the 3 teams was re-analysed by the

123 same analyst and an additional analyst to determine intra- and inter-observer reliability.

124 Intraclass correlation coefficients (ICC) were $\geq 0.93$ for intra-observer reliability and $\geq 0.68$

125 for inter-observer reliability across all variables, which are classed as substantial 126 agreements ${ }^{14}$ and were deemed acceptable based on previous work utilising a similar analyses with wheelchair basketball. ${ }^{15}$.

\section{Statistical Analyses}

Statistical analyses were conducted using the Statistical Package for the Social

134 the explained variance in each of the performance measures as a result of both trunk and arm

135 impairment. An independent variable (trunk and arm group) was only entered into the 136 regression if it was significantly related to the dependent variable being explored. Kruskall137 Wallis tests determined any statistically significant $(P<0.05)$ main effects between both 138 trunk and arm impairment and performance measures. All performance measures that were 139 successfully entered into the regression model or were significantly influenced by trunk or 140 arm impairment (according to the Kruskall-Wallis tests) were analysed further using effect

141 sizes (ES). Calculated as the ratio of the mean difference in relation to the pooled standard 142 deviation of the difference, ES were used to determine the magnitude of any differences 143 between trunk (NT \& T) and arm (PAF, MAF \& GAF) impairments and were defined as 144 trivial $(<0.2)$, small $(0.2-0.6)$, moderate $(0.6-1.2)$, large (1.2-2.0) and very large $(>2.0)$ 145 effects. ${ }^{16}$ 90\% confidence intervals (90\% CI) were also calculated to determine the range 
146 within which the true ES existed. ${ }^{16}$. A meaningful effect was identified when ES were $\geq$ 147 moderate and the 90\% CI did not span into trivial differences.

149 Results

Table 4 presents the explained variance in physical and technical performance 151 according to trunk and arm impairment. Trunk and/or arm impairment contributed to the explained variance observed in all measures of performance except catch success rate and the number of blocks performed, which were removed from further analysis.

INSERT TABLE 4 HERE

Trunk impairment explained some of the variance in all physical measures of performance, with the exception of relative time spent in Z2, Z5 and Z6 (Table 4). Variance ranged from as little as $10.6 \%$ for peak speed, to as much as $23.5 \%$ for time spent in $\mathrm{Z} 1$.

160 Significant and meaningful differences were only observed between trunk groups for relative 161 distance $(P=0.020)$ and time spent in $\mathrm{Z} 1(P=0.003)$, where $\mathrm{T}$ covered more distance $(\mathrm{ES}=$ 0.92 [0.27 to 1.53]) and spent less time in Z1 (ES = -1.15 [-0.48 to -1.77]) than NT (Fig. 1).

164 of performance (Table 4). Although trunk impairment contributed to the variance observed in 165 the number of turnovers forced (10.5\%) and goals scored by driving into the key (14.9\%), 166 differences between trunk groups were neither significant nor meaningful (Fig. 1). The 167 majority of variance in technical measures of performance explained by trunk impairment was for possession duration, passes received, passes and pick-ups made, goals scored and inbounds performed (16.2 to 33.0\%). Significant and meaningful effects existed for $\mathrm{T}$ to 
170 perform fewer inbounds yet score more goals, receive more passes, be in possession longer,

171 make more pick-ups and less passes than NT (Fig. 1).

172

173

INSERT FIGURE 1 HERE

174

175

Arm impairment explained some of the variance and had a significant effect $(P \leq$

176

0.024) on all physical measures of performance ranging from $16.7 \%$ to $47.0 \%$ for the time

177 spent in Z3 and Z5 respectively. Meaningful effects were revealed for both GAF and MAF to

178 cover greater distance, reach higher peak speeds, spend more time in Z3 to Z6 and less time

179 in Z1 than PAF. MAF also spent less time in Z2 than PAF. No meaningful differences were

180 observed between GAF and MAF for any physical measure of performance (Fig. 2).

181

Arm impairment also explained a large amount of the variation in technical performance for all measures except the percentage of goals scored by driving into the key and the number of inbounds performed. Arm impairment accounted for as little as $13.1 \%$ (pick-ups made) to 53.3\% (passes received) of the explained variance and was statistically significant $(P \leq 0.022)$ for all other technical measures of performance (Table 3). Meaningful effects were revealed for GAF and MAF to score more goals, receive more passes, be in possession longer, make more passes, with a higher percentage of one-handed and long passes, make more assists, yet have a lower pass success rate than PAF. GAF made a higher percentage of one-handed passes and made a higher percentage of defensive blocks than MAF (Fig. 3). 

the current study was the first to explore the impact of trunk and arm impairment on physical and technical measures of WR performance during competitive match play at the highest international level.

With regards to physical performance, trunk impairment only had a meaningful effect on the relative distance covered and the time spent at very low speeds (Z1), whereby $\mathrm{T}$ covered greater distances and spent less time in Z1 than NT. Active trunk flexion has been shown to only occur during the initial push, after which the trunk remains relatively stable during sprinting tasks. ${ }^{17,18}$. Therefore trunk function has a key role in acceleration performance, which has previously been demonstrated in WR players. ${ }^{8}$. The increased distance covered by $\mathrm{T}$ could be a consequence of the improved acceleration performance and an accumulation of repeated acceleration activities a player performs, since WR players are 207 frequently required to start from a standstill during games. ${ }^{19}$. Similarly, the reduced time spent in Z1 by T maybe a consequence of trunk function in initial acceleration, whereas trunk function does not contribute to continued acceleration and therefore did not impact upon on 210 the time spent at higher speed zones or peak speed. The seemingly limited contribution of trunk impairment towards performance could be attributed to the type of measures analysed, which did not cover all activities that could possibly be affected by trunk impairment.

213 Altmann et al. ${ }^{8}$ already suggested that trunk impairment can have a significant bearing on 214 acceleration performance, which unfortunately could not be quantified directly within the 215 current study. Moreover, manoeuvrability is also a key indicator of mobility performance in $216 \mathrm{WR},{ }^{20}$ yet it is difficult to quantify objectively, especially in a competition environment. Interestingly, trunk impairment contributed to the explained variance observed in a number of technical variables specific to WR with $\mathrm{T}$ shown to score more goals, spend more time in possession, receive a higher number of passes and make a higher number of pick-ups. 
220 All these parameters are indicators of offensive game efficiency. ${ }^{6,7}$. No meaningful effects of

221 trunk impairment on defensive aspects of performance were revealed (number of turnovers

222 forced / blocks performed), which may have been anticipated based on the previous

223 association between trunk function and the impulse of a hit in WR. ${ }^{8}$. Observations that NT

224 performed more passes and inbounds was likely a tactical decision to help enable players

225 with some trunk function to carry out these offensive duties. Overall, results implied that

226 trunk function has more of an impact on offensive aspects of WR performance.

Unlike trunk impairment, arm impairment was shown to impact upon all physical

measures of performance measured in the current study, although differences were only observed between players with PAF in relation to both MAF and GAF. Players with superior arm function (MAF and GAF) covered more distance, reached higher peak speeds, spent less time in low speed zones (Z1 \& Z2) and more time in moderate to maximal speed zones (Z3-

Z6). The fact that superior arm function was associated with greater peak speeds supported previous findings whereby arm impairment was shown to affect sprinting performance $>2$ m. ${ }^{8}$ It has been suggested that the trunk is actively involved during initial acceleration, yet once momentum has been developed it merely acts as a stable base for the arms to drive the wheels, ${ }^{8,21}$ which is in line with the current findings.

Proximal muscle weakness is the key difference between athletes with PAF and those 238 with both MAF and GAF. Therefore the differences in physical performance observed 239 between athletes with PAF and both MAF and GAF demonstrated the important role of 240 proximal muscles of the arms during WR-specific propulsion. Superior shoulder and triceps 241 function is likely to allow for improved propulsion kinematics and kinetics, with both a 242 longer push angle and greater force application anticipated respectively. ${ }^{22}$. Alternatively, 243 since no meaningful differences in physical performance were observed between MAF and 244 GAF, it suggests that distal muscle weakness has a minimal effect on wheelchair handling 
245 activities specific to WR. Although the impact of finger function on physical performance in

246 WR has never investigated before, this observation is in line with what has been

247 recommended in wheelchair racing with finger function not deemed essential since athletes

248 typically contact the wheel with the hands as opposed to grasping the wheel or push rim

249 during propulsion. ${ }^{23}$

250 As anticipated, arm impairment had a large bearing on ball handling activities specific

251 to WR, since it accounted for some of the explained variance observed in the majority of

252 technical measures examined. Both MAF and GAF were shown to score more goals, have

253 more possession, receive and make more passes, with a higher percentage of one-handed and

254 long passes and provide more assists than PAF. Since all of these parameters are associated

255 with scoring goals or the creation of goals, it seemed clear that proximal muscle weakness

256 prevented WR players from effectively performing offensive, technical duties. Although pass

257 success rate was actually shown to be higher in individuals with proximal muscle weakness

258 (PAF), this was likely related to the finding that these individuals attempted fewer one-

259 handed and long passes, which are expected to be more challenging.

260 Distal muscle function further facilitated offensive ball handling activities associated

261 with WR since more pick-ups were made and passes received and a higher percentage of one-

262 handed passes made were observed for players with GAF compared to MAF. The ability to

263 perform a one-handed pass is a particularly valuable asset for a WR player, as they are often

264 blocked or 'picked' by more than one opponent. In these situations offloading the ball to a

265 teammate can be difficult and the ability to raise the ball up with one hand to make a pass

266 clearly requires hand and finger function. GAF also performed a higher percentage of

267 defensive blocks, although this observation was more likely linked to the finding that these

268 players receive more passes and spend more time in possession and as a consequence

269 performed a lower percentage of offensive blocks. Therefore, arm function may not play a 
270 critical role in defensive blocking, however the confounding factor could be the type of

271 opponent that players were blocking. Despite this, distal upper limb function did impact on

272 the performance of defensive WR activities since more turnovers, which were achieved by a

273 combination of steals and interceptions, were forced by GAF. This demonstrates the impact

274 that a combination of triceps, hand and finger function can have on both offensive and 275 defensive WR activities.

276

277 Limitations

278

The current study provided a novel insight into the contribution of trunk and arm

279 impairment on physical and technical aspects of WR performance during competition.

280 However, such an approach is accompanied by some limitations. Firstly only athletes with an

281 eligible WR classification can be investigated in a competitive environment, which limits the combination of trunk and arm impairments. For instance, players with some trunk function (0.5-1.5) cannot have good arm function (2.5-3.5) since they could exceed the overall

284 classification eligible for participation. Furthermore, combinations of arm and trunk scores 285 lead to the sports class of the athlete. The number of athletes per trunk and arm combination 286 was low and for some combinations, there were no participating athletes at all. As a consequence, analysis of any differences in athletes within one class, but with different combinations of arm and trunk scores could not be made. Similarly, it can also be difficult to make direct inferences between the impact of impairment and WR performance during competition due to the roles on court players adopt. Low-point players are thought to occupy more defensive roles on court, where a key responsibility is to pick/block opponents, whereas high-point players are often afforded offensive roles that involve ball handling and scoring 293 goals. ${ }^{3,6,24}$ Therefore, it remains unclear whether the players' role on court influences their 294 performance more than their specific impairment, as tactics and team line-ups may also 
295 influence performance and as such the findings must be interpreted with caution. Despite this, 296 many of the findings currently observed under the constraints of competition complement 297 what has been observed during standardised field testing. ${ }^{8}$

\section{Practical Applications}

- Scientific research during competition can play an important role in understanding the impact of impairment on performance, since players are likely to demonstrate maximal effort under these conditions. Subsequently, data on performance collected in a high-level competition are needed to support the development of evidence-based classification systems in Paralympic sports.

- To understand more about the specific contribution of arm impairment, future research at low-point WR tournaments would be advisable, where the majority of players have NT, meaning the impact of arm impairment on performance can be determined under more controlled conditions.

- In addition to impairment, players roles on court (defensive/offensive) can also influence activity profiles, meaning that future research using standardised field tests would further our understanding of the effect of impairment on performance by minimising the influence of potential confounding factors.

- Coaches who wish to adopt a passing style of play may benefit from selecting a lineup with players of superior arm function, whereas those who wish to minimise the number of passes from offensive situations may wish to recruit players with superior trunk function. 


\section{Conclusions}

The current study has revealed that during competition, both trunk and arm

320 impairment impact upon physical and technical measures of performance specific to WR.

321 Trunk impairment was shown to mainly impact upon technical measures that are associated

322 with offensive roles, whereas arm impairment was shown to affect all physical measures and

323 both offensive and defensive aspects of technical performance. Active finger function (GAF)

324 had little bearing on WR mobility performance, yet did facilitate the performance of a small 325 number of technical skills vital to WR performance.

326

\section{Acknowledgements}

328 The authors would like to thank the Peter Harrison Foundation and UK Sport for their 329 financial support, the International Wheelchair Rugby Federation and the players for 330 participating in this study. Our appreciation is extended to Mike Hutchinson, Jan van der 331 Scheer and Ben Stone for their assistance with data collection.

332 
1. International Wheelchair Rugby Federation. Wheelchair rugby international rules. 2015. $\quad$ [accessed $2017 \quad$ Jan 31]. $\quad$ Retrieved from http://www.iwrf.com/resources/iwrf_docs/wheelchair_rugby_international_rules_201 5_english.pdf

2. Tweedy SM, Vanlandewijck YC. International Paralympic Committee position stand - background and scientific principles of classification in Paralympic sport. Brit $J$ Sports Med 2011;45:259-61.

3. Rhodes JM, Mason BS, Perrat B, Smith MJ, Malone LA, Goosey-Tolfrey VL. Activity profiles of elite wheelchair rugby players during competition. Int $J$ Sports Physiol Perform 2015;10:318-25.

4. Rhodes JM, Mason BS, Malone LA, Goosey-Tolfrey VL. Effect of team rank and player classification on activity profiles of elite wheelchair rugby players. J Sports Sci

5. Sarro KJ, Misuta MS, Burkett B, Malone LA, Barros RML. Tracking of wheelchair rugby players in the 2008 demolition derby final. J Sports Sci 2010;28:193-200.

6. Molik B, Lubelska E, Kosmol A, Bogdan M, Yilla AB, Hyla E. An examination of 351 the International Wheelchair Rugby Federation classification system utilizing parameters of offensive game efficiency. Adapt Phys Activ Q 2008;25(4):335-51.

7. Morgulec-Adamowicz N, Kosmol A, Bogdan M, Molik B, Rutkowska I, bednarczuk G. Game efficiency of wheelchair rugby athletes at the 2008 Paralympic Games with regard to player classification. Hum Movement 2010;11(1):29-36.

8. Altmann VC, Groen BE, Hart AL, Vanlandewijck YC, van Limbeek J, Keijsers NL. The impact of trunk impairment on performance-determining activities in wheelchair rugby. Scand J Med Sci Sports 2017;27(9):1005-1014. 
9. Altmann VC, Groen BE, Hart AL, Vanlandewijck VC, Keijsers NLW. Classifying trunk strength impairment according to the activity limitation caused in wheelchair rugby performance. Scan J Med Sci Sports 2018;28(2):649-657.

10. International Wheelchair Rugby Federation (IWRF) classification manual, $3^{\text {rd }}$ edition revised 2015.

Retrieved

from: http://www.iwrf.com/resources/iwrf_docs/IWRF_Classification_Manual_3rd_Edition _rev-2015_(English).pdf

11. Hislop HJ, Montgomery J. Daniels and Worthingham’s Muscle Testing: Techniques of Manual Examination, $8^{\text {th }}$ ed 2007. Philadelphia, PA. USA: WB Saunders.

12. Altmann VC, Groen BE, Groenen KHJ, Vanlandewijck YC, van Limbeek J, Keijsers NLW. Construct validity of the trunk impairment classification system in relation to objective measures of trunk impairment. Arch Phys Med Rehabil 2016;97(3):437-444.

13. Rhodes J, Mason B, Perrat B, Smith M, Goosey-Tolfrey V. The validity and reliability of a novel indoor player tracking system for use within wheelchair court sports. J Sports Sci 2014;32(17):1639-47.

14. Landis RJ, Koch GG. The measurement of observer agreement for categorical data. Biometrics 1977;33:159-74.

15. De Witte AMH, Hoozemans MJM, Berger MAM, van der Woude LHV, Veeger HEJ. Do field position and playing standard influence athlete performance in wheelchair basketball? J Sports Sci 2016;34(9):811-20.

16. Batterham AM, Hopkins WG. Making meaningful inferences about magnitudes. Int J Sports Physiol Perform 2006;1(1):50-7.

17. Vanlandewijck YC, Verellen J, Beckman E, Connick M, Tweedy SM. Trunk strength effect on track wheelchair start: Implications for classification. Med Sci Sports Exerc 2011;43(12):2344-51. 
18. West CR, Campbell IG, Goosey-Tolfrey VL, Mason BS, Romer LM. Effects of abdominal binding on field-based exercise responses in Paralympic athletes with cervical spinal cord injury. J Sci Med Sport 2014;17:351-5.

19. Sporner ML, Grindle GG, Kelleher A, Teodorski EE, Cooper R, Cooper RA. Quantification of activity during wheelchair basketball and rugby at the National Veterans Wheelchair Games: a pilot study. Prosthet Orthot Int 2009;33(3):210-7.

20. Mason BS, Porcellato L, van der Woude LHV, Goosey-Tolfrey VL. A qualitative 391 examination of wheelchair configuration for optimal mobility performance in wheelchair sports: a pilot study. J Rehabil Med 2010;42:141-9.

21. Vanlandewijck YC, Verellen J, Tweedy S. Towards evidence-based classification in wheelchair sports: impact of seating position on wheelchair acceleration. J Sports Sci 2011;29(10):1089-96.

22. Dallmeijer AJ, van der Woude LHV, Veeger HEJ, Hollander AP. Effectiveness of 397 force application in manual wheelchair propulsion in persons with spinal cord injuries. Am J of Phys Med Rehabil 1998;77(3):213-21.

23. Grey-Thompson T, Thompson I. Wheelchair racing. In: Goosey-Tolfrey VL, editor. 400 401 Wheelchair Sport - A Complete Guide for Athletes, Coaches and Teachers. Human Kinetics, Leeds, UK; 2010. p. 133-50.

24. Orr K, Malone LA. Wheelchair rugby. In: Goosey-Tolfrey VL, editor. Wheelchair 404 Sport - A Complete Guide for Athletes, Coaches and Teachers. Human Kinetics, Leeds, UK; 2010. p. 151-166. 


\section{Figure Legends}

407 Figure 1 - Effect sizes ( \pm 90\% CI) between trunk impairment groups for all physical and 408 technical measures of performance. A positive effect demonstrates that $\mathrm{T}$ scored higher for 409 that variable than NT.

410 Figure 2 - Effect sizes ( \pm 90\% CI) between arm impairment groups for all physical measures 411 of performance. A positive effect represents a higher score for the more functional arm 412 impairment.

413 Figure 3 - Effect sizes ( $\pm 90 \%$ CI) between arm impairment groups for all technical 414 measures of performance. A positive effect represents a higher score for the more functional 415 arm impairment. 


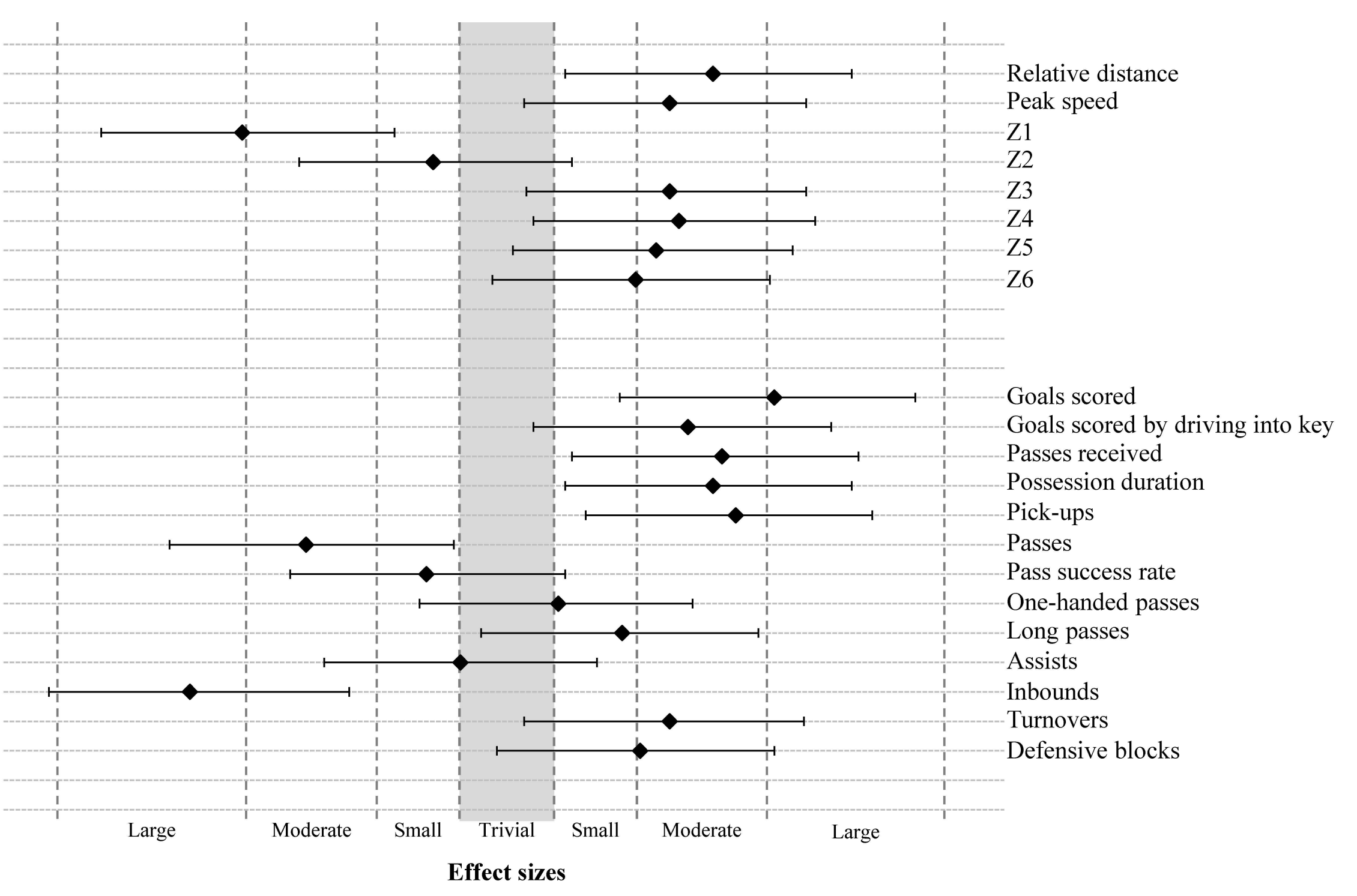




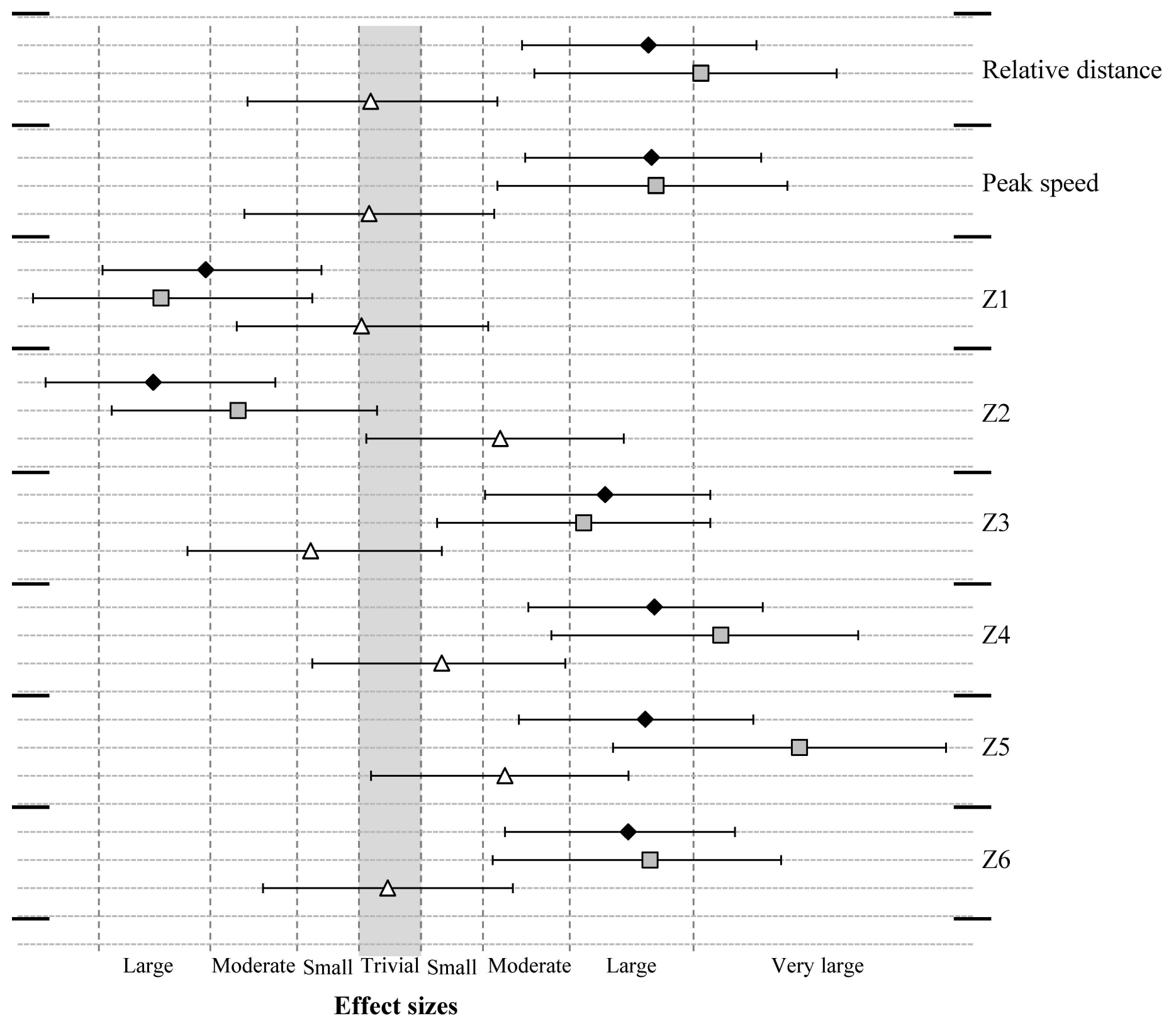


- Poor v Mod $\square$ Poor v Good $\triangle$ Mod v Good

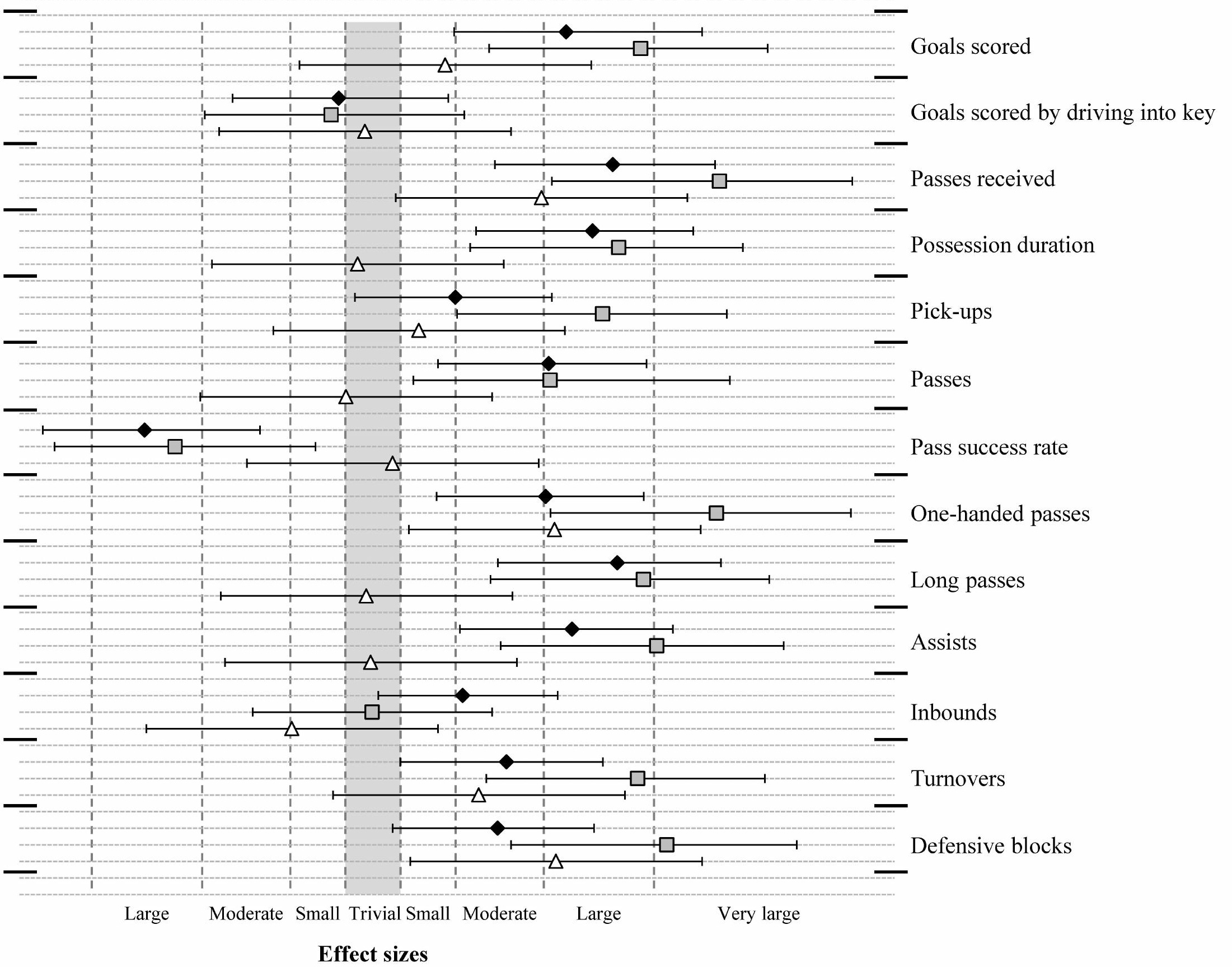


Table 1 - Combination of trunk and arm impairments from the current cohort of participants.

\begin{tabular}{cccccc}
\hline & \multicolumn{5}{c}{ Trunk score } \\
Arm score & $\mathbf{0}$ & $\mathbf{0 . 5}$ & $\mathbf{1 . 0}$ & $\mathbf{1 . 5}$ & Total (n) \\
\hline $\mathbf{0 . 5}$ & 4 & 0 & 1 & 0 & 5 \\
$\mathbf{1 . 0}$ & 3 & 1 & 0 & 0 & 4 \\
$\mathbf{1 . 5}$ & 0 & 2 & 0 & 1 & 3 \\
$\mathbf{2 . 0}$ & 8 & 3 & 1 & 1 & 13 \\
$\mathbf{2 . 5}$ & 2 & 3 & 0 & NE & 5 \\
$\mathbf{3 . 0}$ & 1 & 0 & NE & NE & 1 \\
$\mathbf{3 . 5}$ & 0 & NE & NE & NE & 0 \\
Total (n) & 18 & 9 & 2 & 2 & 31
\end{tabular}

NE = combination would have resulted in a classification score deemed 'not eligible' for WR 
Table 2 - Speed zones used to quantify exercise intensity during match-play

\begin{tabular}{lll}
\hline Zone & Intensity & Speed threshold $\left(\mathbf{m}^{-\mathbf{s}^{-1}}\right)$ \\
\hline Z1 & Very low & $<0.50$ \\
Z2 & Low & $0.50-1.49$ \\
Z3 & Moderate & $1.50-2.49$ \\
Z4 & High & $2.50-2.99$ \\
Z5 & Very high & $3.00-3.49$ \\
Z6 & Maximal & $\geq 3.50$ \\
\hline
\end{tabular}


Table 3 - Description of the technical activities used to analyse performance

\begin{tabular}{|c|c|c|}
\hline Activity & Type & Description \\
\hline \multicolumn{3}{|l|}{ Goals } \\
\hline Goals scored & $n$ & Total number of goals scored \\
\hline Driving into key & $\%$ & Goals scored by carrying the ball into the key \\
\hline Received pass in key & $\%$ & Goals scored by receiving a pass whilst in the key \\
\hline \multicolumn{3}{|l|}{ Catching } \\
\hline Passes received & $n$ & Number of passes received that were deemed 'catchable' \\
\hline Catch success rate & $\%$ & Passes successfully caught \\
\hline Possession duration & $\bar{x}$ & Time spent in possession of the ball \\
\hline Pick-ups & $n$ & Number of loose balls recovered \\
\hline \multicolumn{3}{|l|}{ Passing } \\
\hline Passes & $n$ & Total number of passes attempted by a player \\
\hline Pass success rate & $\%$ & Passes that reached their target, regardless of being caught \\
\hline One-handed passes & $\%$ & Passes attempted with one hand \\
\hline Long passes & $\%$ & Passes played over or past an opponent \\
\hline Assists & $n$ & Pass directly preceding a goal scored \\
\hline Inbounds & $n$ & Pass made to restart the game from goal- or side-line \\
\hline
\end{tabular}

\section{Defending}

Turnovers $\quad n \quad$ Forcing a mistake from opponents i.e. steal/interception

Blocks $\quad n \quad$ Number of hits and picks made on an opponent's chair

Defensive blocks $\quad \% \quad$ Blocks that were made when team were not in possession

$n=$ frequency; $\%=$ percentage; $\bar{x}=$ mean 
Table 4 - The explained variance in performance from the multiple linear regression models and the mean ( \pm SD) for the performance variables according to athlete's trunk and arm group

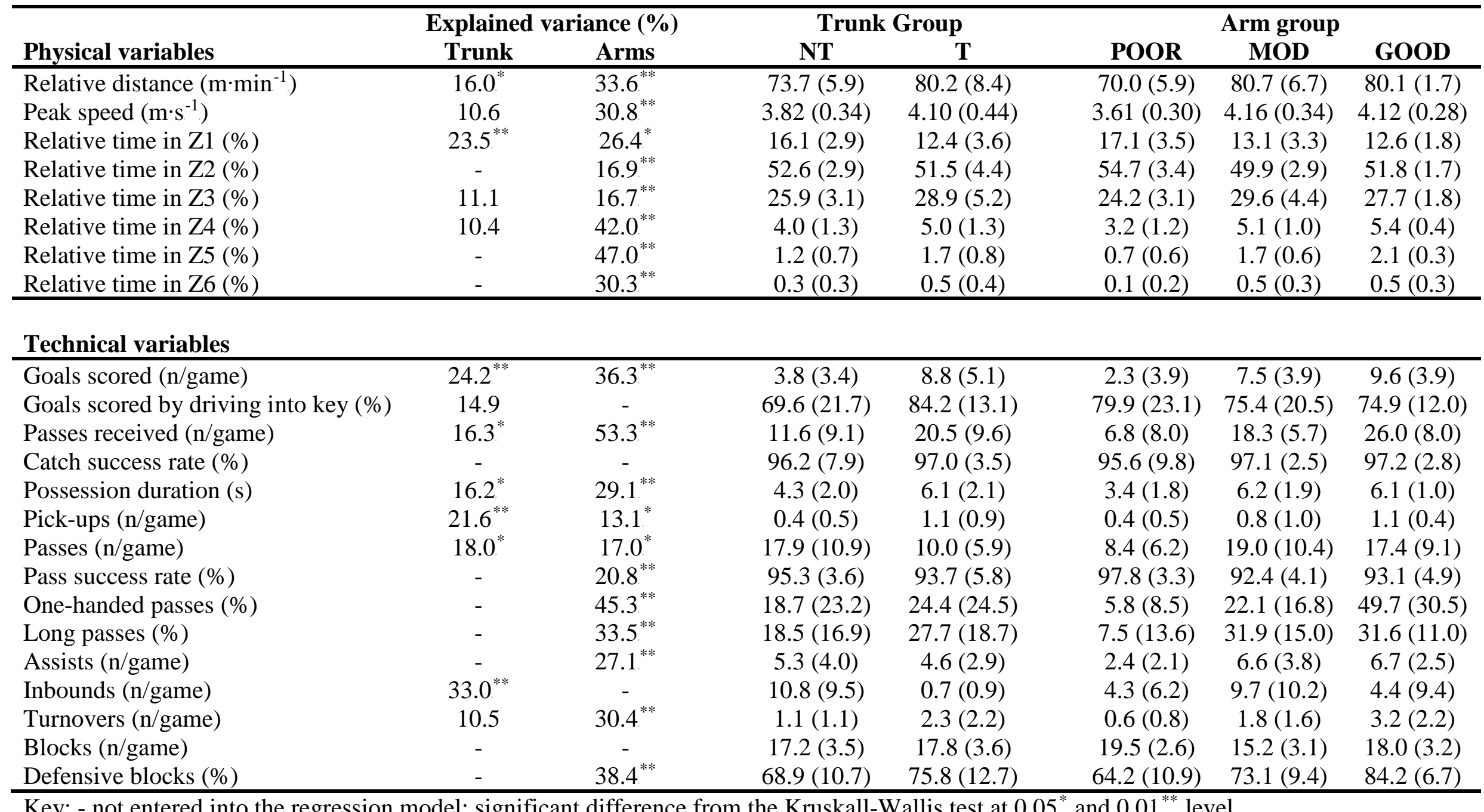

Key: - not entered into the regression model; significant difference from the Kruskall-Wallis test at $0.05^{*}$ and $0.01^{* *}$. level. 